\author{
Ávila, Mireia. \\ Graduada en Bellas Artes, Universidad Politécnica de Valencia.
}

\title{
PROCESOS EN LA MEMORIA; Al margen de lo familiar.
}

\author{
TIPO DE TRABAJO
}

Comunicación.

PALABRAS CLAVE

Procesos, memoria, cera, realidad, invisible.

KEY WORDS

Processes, memory, wax, reality, invisible.

\section{RESUMEN}

Dentro del ámbito de la producción artística, mi actual preocupación reside en los procesos gráficos y digitales que permiten investigar en el campo audiovisual. Esta preocupación me lleva a trabajar con la fotografía analógica llevándola a su parte más experimental, desarrollando técnicas plásticas gracias a la tecnología. La investigación se centra en recursos alrededor del transfer y la investigación de sus posibilidades sobre cera reciclada. El proyecto se centra especialmente en la parte procesual más que en el resultado mismo. Este proceso conlleva una previa manipulación de las imágenes a registrar sobre diferentes ceras, se trabaja con la idea del soporte como extensión de significado.

Mediante el control y manipulación de impresoras específicas, se consiguen modificar resultados en los procesos. Las tecnologías actuales ofrecen este tipo de investigaciones plásticas y digitales. Aunque otro aspecto importante es el soporte, es más la trayectoria hasta llegar a éste, la que le aporta significado a la obra.

Las imágenes de la infancia con las que trabajo una vez registradas sobre el soporte de ceras, permiten que la luz pase a través de ellas. Por ello, cobran significado vistas a contraluz o retro iluminadas. Los conceptos clave de las piezas giran en torno a la memoria individual, el recuerdo y la identidad familiar.

Las piezas bidimensionales y tridimensionales que produzco constituyen una colección centrada en conceptos como la fragilidad de un recuerdo o la pérdida de información en cuanto a la identidad, y la memoria real que cada individuo guarda e interpreta. Por ello, las imágenes se registran sobre cera, un soporte frágil y translúcido como un recuerdo, fácil de romperse y hacerse pedazos. El soporte como extensión del significado. El trabajo guarda referentes técnicos de la electrografía como conceptuales tales como Joan Fontcuberta, Walter Benjamin o Christian Boltanski.

\section{ABSTRACT}

My current artistic concern is on graphics and digital processes, which allow me to research in the audiovisual area. This concern brings me to work with analog photography, working on its experimental part and developing art techniques through technology. The research focuses on resources around transfer and the possibilities of this technique on recycled wax. The project focuses especially on the process rather than the final artwork. This process involves a previous manipulation of images, which then could be recorded on different waxes. It works with the idea of the base as an extension of meaning.

Once specific printers are controlled and manipulated, the results in artistic processes could be modified. Current technologies offer this kind of artistic and digital researches. Although another important aspect is the base (support, holder), the path to obtain that base is significant, because it is which gives meaning to the artwork. My work is built with old and childhood photographs, which after be registered on waxes, the pieces let light pass through them. Therefore, these acquiere meaning when these are viewed backlit or retro illuminated. The key concepts of the pieces are individual memory, family identity and invisibility. 
Two-dimensional and three-dimensional pieces that I produce are a collection focused on concepts such as the fragility of a memory or loss of information about the identity that each person stores and performs in his mind. Therefore, images are transferred onto wax, on a fragile and translucent base, as a memory, easy to break and shatter. The base as extension of the meaning. The work keeps technical models of referency from electrography and conceptual referents such as Joan Fontcuberta, Walter Benjamin and Christian Boltanski.
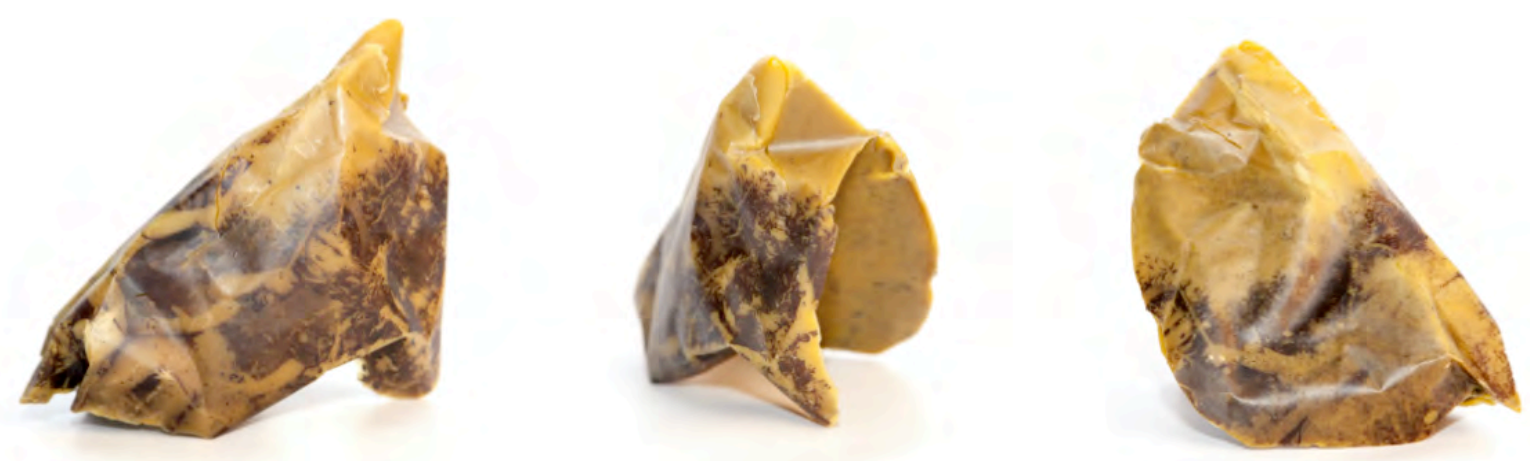

llustración 1 - ÁVILA, M. Sin título. Medidas variables. 2015.

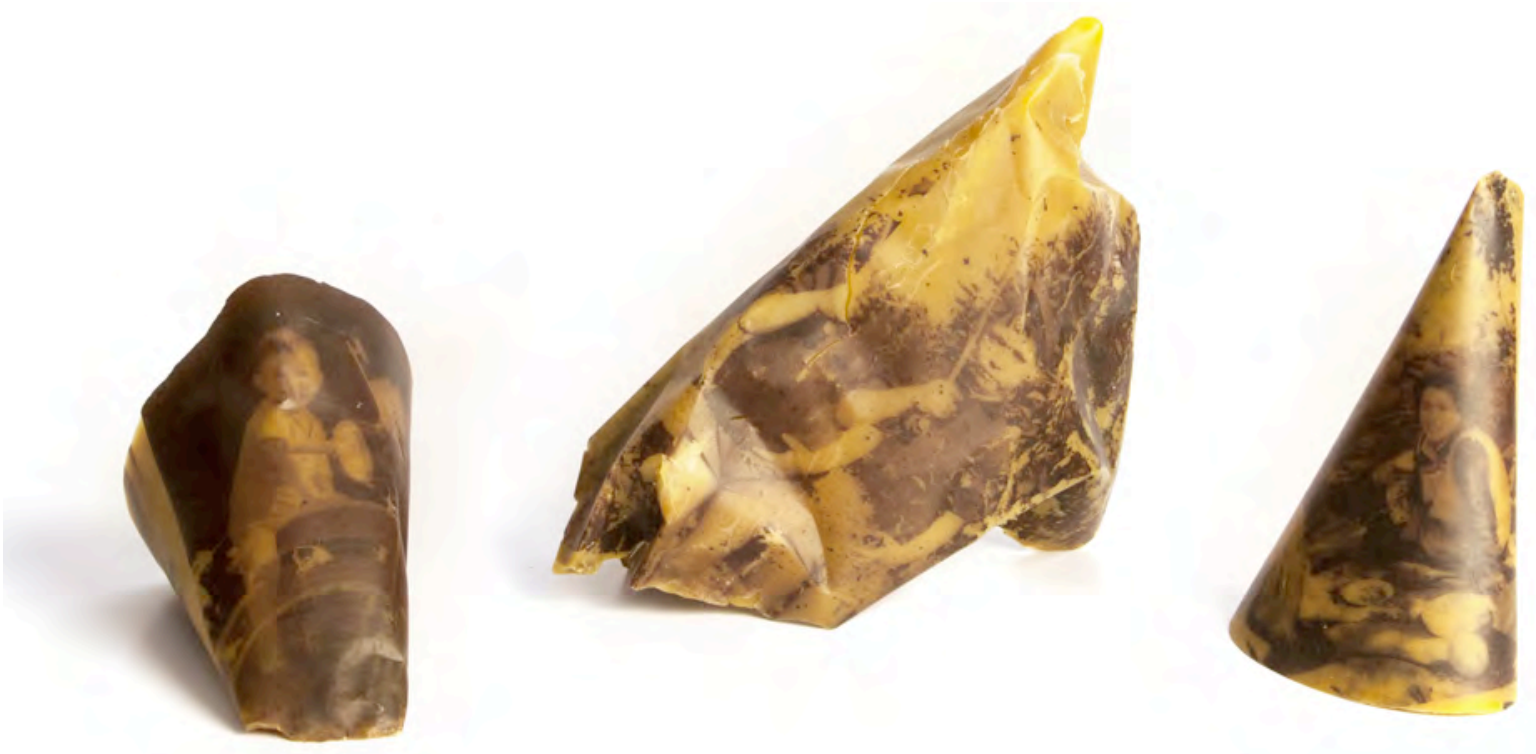

Ilustración 2 - ÁVILA, M. Sin título. Medidas variables. 20152. 


\section{CONTENIDO}

\section{INTRODUCCIÓN}

La investigación dentro de la producción artística es constante en la obra que se presenta en este trabajo. Se trata de un proyecto centrado en los procesos gráficos y digitales que indagan dentro del campo audiovisual, desde la fotografía analógica, digital o las electrografías en busca de otras miradas. Los dispositivos tecnológicos permiten experimentar en conceptos y medios que juegan con la realidad. En este caso, una realidad vista desde la memoria individual que poseemos sobre un recuerdo que se manipula dentro del proceso de producción de la obra. La actual preocupación en estas experimentaciones me llevan hasta conceptos como la invisibilidad del recuerdo o la pérdida de información en cuanto a la identidad, sobre registros de imágenes tratados sobre ceras recicladas.

Se trata de un proyecto fotográfico trasferido sobre unas piezas obtenidas mediante un proceso gráfico y digital que me permite trabajar con soportes moldeables y manipulables como es la cera. Está concebida como una obra diáfana, en la que el soporte es la extensión del significado de la obra. Se busca trabajar la fragmentación técnica y conceptual, ya que concepto y soporte van estrechamente cogidos de la mano. Hablamos de esta idea de soporte, ya que es éste quien complementa el significado de la obra.

Transferir es la capacidad de trasladar saberes de un contexto a otro. Por lo tanto, entendemos que realizar una transferencia es trasladar todo tipo de procedimientos o estrategias, habilidades o destrezas de un contexto a otro, así como relacionar un campo de conocimiento con otro para entenderlo. Por esto se considera una parte del proceso importante, obviando sus aspectos más técnicos o formales.

La transferencia, y en nuestro caso los procesos, también la podemos establecer como la idea del Doble. Atendiendo a la clasificación que establecen José Ramón Alcalá y Jesús Pastor ${ }^{1}$ como identidades significantes del doble sobre la idea de transferencia, en donde los resultados son desde la generación de imágenes con su inicio, creando un bucle con una larga cadena de transformaciones, en donde la idea de visión a través del espejo adquiere una especial relevancia, y citan:

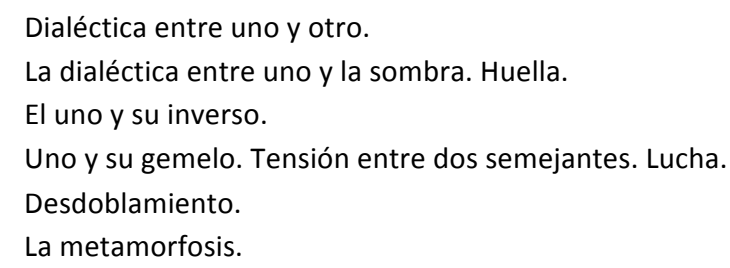

Se da una fuerte importancia al proceso de producción debido a que es lo que da carácter y significado a la pieza final. Se trata de dominar contextos (de dónde surge la imagen y a dónde va) y procesos (registro, mediación, impresión, soportes temporales y soporte definitivo). Entendemos que al soporte definitivo se le añade un nuevo sentido, de forma que puede tener una idea de narración ligada al soporte. Así es como sostiene el filósofo Michel Foucault ${ }^{2}$, «el archivo es el sistema de "enunciabilidad" a través del cual la cultura se pronuncia sobre el pasado».

Rodando un poco más la idea de importancia en el proceso de la obra como afirma Walter Benjamin, "el sistema de reproducción se basa en el concepto de dos moldes estándar, pero en los actuales sistemas de reproducción electrónicos este concepto se hace más ambiguo pudiendo decir que en éstos ya no existe un molde estándar debido a que la obra es ya su propia variación, no su propia identificación." ${ }^{3}$

Recordar es menos reflexionar, analizar y explicar que hacerse presente, hallar un lugar, soñar, narrar, tejer, escuchar, olfatear, apoderarse de un chispazo, una imagen potente y fugaz. En El narrador de W. Benjamin se emplea la imagen de una red que todas las historias forman al final, y en Una imagen de Proust se habla de la actividad de "tejer el recuerdo", así como la "obra de Penélope" en la que están entrelazados recuerdo y olvido.

A día de hoy, la obra no se limita a planos bidimensionales o estructuras secuenciales a modo de series, repeticiones o sistemas modulares; la obra va cogiendo forma, volumen, dimensión, no se puede clasificar en un campo único. Se podría resumir en fotografía, pintura, grabado o escultura.

\footnotetext{
${ }^{1}$ ALCALÁ, J. R., PASTOR, J. Procedimientos de Transferencia en la Creación Artística, p. 13.

${ }^{2}$ FOUCAULT, M. The Archaeology of Knowledge, p. 129.

${ }^{3}$ BENJAMIN, W. Autobiographische Schriften / Escritos autobiográficos, capítulo 1.
} 

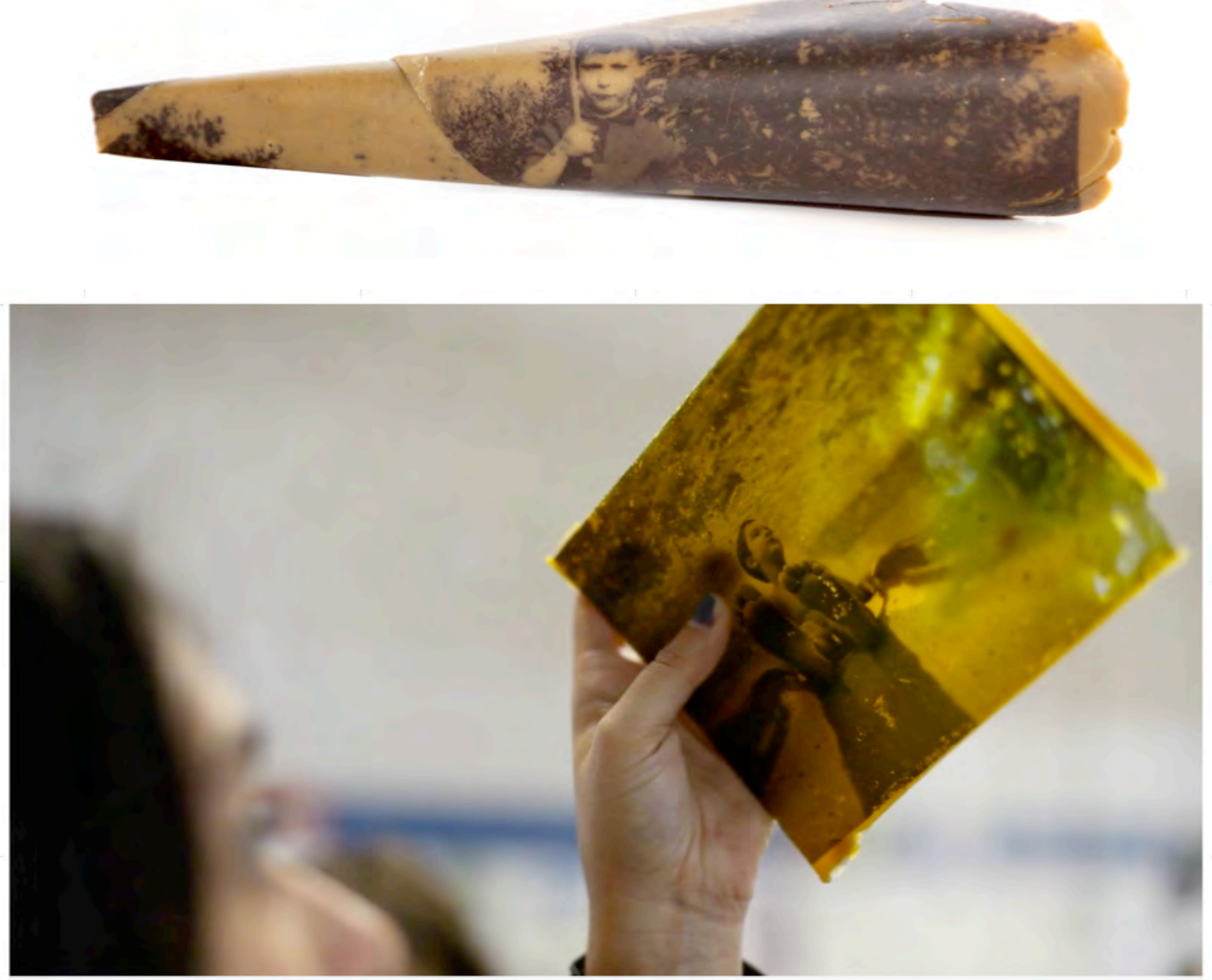

llustración 3 - ÁVILA, M. Sin título. 20 x 15 cm. 2013.

\section{DESARROLLO}

El trabajo se centra tanto en la parte procesual como en el resultado mismo, ya que es el proceso quien da carácter a las piezas. La obra parte del campo audiovisual, y lleva la fotografía a su parte más experimental. El conjunto de piezas forma una colección centrada en conceptos como la fragilidad de un recuerdo, la recuperación de la memoria individual y la pérdida de identidad. Identidad relacionada con aquello que entendemos por "familiar", ya que el espectador anónimo puede reconocer e re-interpretar personalmente las situaciones propias del artista. La cera, un soporte tan frágil y translúcido como lo es un recuerdo, fácil de romperse y hacerse pedazos. El soporte como extensión del significado. La invisibilidad de un recuerdo, el individuo como eje central.

Se trata de reinterpretar o recodificar contextos familiares (y por tanto, relativos a la identidad personal) dentro del ámbito de la memoria individual, de aquello que consideramos real o no. La recuperación de la memoria («recordar como una actividad vital humana define nuestros vínculos con el pasado, y las vías por las que recordamos nos define en el presente») reestructura los diálogos pasado-presente y sincronía-diacronía, más allá del triple interés (interés por el 'yo', por la realidad exterior y por el propio arte) que se aprecia en buena parte del arte del siglo XX tanto en las vanguardias como en las neovanguardias.

Dentro de los referentes hablaríamos siempre de la fotografía y por otro lado del registro digital propio del escáner, fotografía digital, electrografía e Internet. En la actualidad y durante los años 90 fueron y son muchos los artistas que utilizan esta técnica como nuevo concepto del lenguaje híbrido. Así se dividen los referentes entre conceptuales (como Walter Benjamin, Christian Boltanski o Joan Fontcuberta) y técnicos (como Robert Rauschenberg, Jesús Pastor, Paco Rangel o Rubén Tortosa).

La idea que transcribe esta técnica se entiende a través del concepto de huella, sobre el cual Derrida habló de nuevas formas en cuanto a la temporalización y la espacialización. El significado de huella no está nunca presente, está en una otredad; estando presente está ausente. El desvanecimiento forma parte de la estructura de la huella. No es "presencia sino el simulacro de presencia lo 
que se desvanece, se desplaza y que de alguna manera no ocurre. Lo presente se convierte en signo del singo, en huella de la huella". ¿Se puede entonces reflexionar sobre la esencia del ser en la huella? ¿Sería una estética de la huella la verdadera estética de la ausencia, como huella de lo presente y como desvanecimiento de la huella? El desvanecerse, desplazarse, remontarse como momentos de la dinámica de la huella, como procesualidad de la huella, constituyen desde luego estrategias (de la huella), que a su vez forman parte del canon de una estética de la ausencia.

Como afirma J. R. Alcalá en el texto ¿Puedo mirar? Reinventando la mirada-artística- en la era del dispositivo tecnológico ${ }^{4}$ sobre el trabajo de su compañero Rubén Tortosa, "De la imagen digital interesa por fin su superficie, lo que constituye en sí mismo toda una paradoja, que sólo cobra sentido desde el concepto metafórico del tránsito no a la superficialidad del código gráfico, si no a la esencialidad de la piel de la imagen, que no es sino la re-construcción de la mirada, proponiendo una alter-digitalidad inédita que la re-invente, dándole otras oportunidades que no sea la existencia virtual dentro de la pantalla del dispositivo electrónico."

Entre los rasgos más característicos de la obra destacan aquellos que le aportan ese significado de huella en el tiempo que se ha mencionado anteriormente. Tales como los remaches sobre el fondo, las modificaciones sobre el registro fotográfico, la manipulación del soporte temporal, o las rupturas del propio material pudiendo estar previamente planificadas o dando lugar a la accidentalidad en el proceso de producción. En accidente controlado, como se puede observar en la siguiente llustración (2).

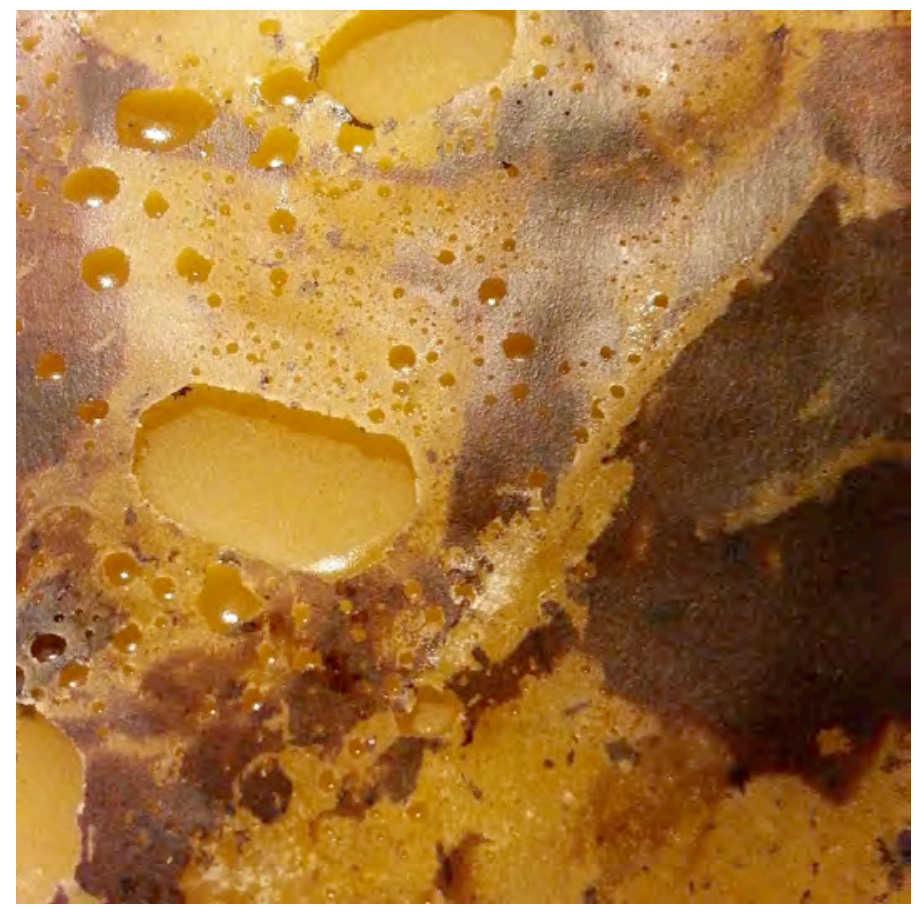

Ilustración 4 - detalle pieza

Lo visible y lo invisible, lo real y lo virtual sobre el significado de la obra, debe cobrar un protagonismo en el paso final, siendo así también un objetivo a tener en cuenta. Este hecho viene a referirse a la magnitud de visión que alcanza la obra, la cual puede ser observada por cualquiera de sus lados, jugando con la translucidez del material.

La vida ordinaria, lo cotidiano, lo real. Se quieren recorrer con extrañeza vivencias, preguntas y sensaciones que, lejos de parecer congeladas, parecen increpar e irrumpir en la misma escritura y en el mismo espectador. Se plantean esas relaciones entre el recuerdo y el olvido, o la comprensión y el extrañamiento.

Las primeras obras que realicé, dispuestas en cajas de luz retroiluminadas con leds fríos (llustraciones $5,6,7$ y 8), juegan con la dualidad, el espejismo dentro de la fragmentación. Las obras dan lugar a que el espectador se aproxime o distancie dependiendo de lo que le sugiera la pieza. Por ejemplo, el políptico (Ilustración 4) invita a ser visto desde la proximidad, donde se aprecian todas las roturas, surcos, lagunas y registros manipulados que la componen, aunque a diferencia del resto de obras puede observarse perfectamente desde la lejanía.

\footnotetext{
${ }^{4}$ Véase más información en ALCALÁ, J. R. ¿Puedo mirar? Reinventando la mirada -artística- en la era del dispositivo tecnológico. Disponible en: http://www.rubentortosa.com/?p=179
} 


\section{CONCLUSIONES}

Dentro de la era digital, lo que más importa en este proyecto es la manera de hacerlo y el comprender como se ha gestado su proceso y por consecuente la obra en sí, la materialidad como fin y objeto. Por ello, hablamos de encontrar otras miradas, otras formas de ver, y de lo que se quiere transmitir. Se trata de buscar una obra de enfoque genérico. No hay que limitarse a hablar de pintura, grabado, fotografía, o escultura ni de otras disciplinas concretas. La obra coge forma, volumen, dimensión, no se puede clasificar en un campo único. Como punto de partida, la fotografía, y la experimentación con la misma a través de procesos gráficos y digitales, hasta llegar al concepto escultórico como soporte.

Al trazar dos vías paralelas de lectura en la obra, se deben comprender ambas a la par (ya que se complementan y emergen la una de la otra) desde su lectura más técnica y su reflexión conceptual. Por otra parte, se indaga tanto en el detalle (originado por el campo de la fotografía), como en la pérdida de información de la imagen y su significado. Esto se debe a que la obra son sumas de acontecimientos que fluyen en un tiempo natural, lo que hace que lo importante no sea el contenido biográfico en sí mismo, sino la estructura de este contenido.

El trabajo también concluye con el objetivo de hacer llegar el mensaje de la idea, de forma que la obra haga confluir pasado, presente y futuro en los lugares de la memoria individual. El que recuerda es un espectador anónimo capaz de reflexionar sobre su propio recuerdo e identidad. Se da una fuerte importancia al proceso de producción debido a que es lo que da carácter a la pieza. Se trata de dominar contextos (de dónde surge la imagen y a dónde va) y procesos tanto manuales como tecnológicos.
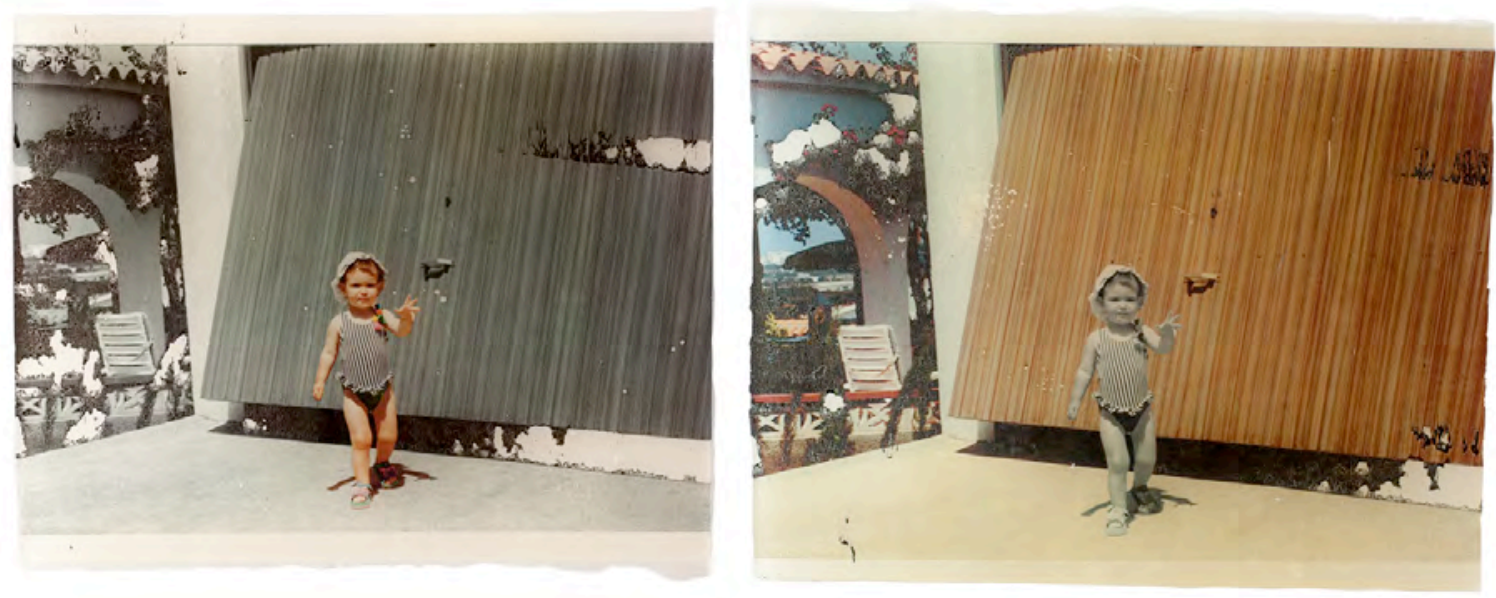

llustración 5 - ÁVILA, M. Serie "Identidad", registro sobre cera. 30 × 24 cm. 2014.

Se invita a reflexionar sobre la producción, el uso, el consumo, el reciclaje, el olvido y la difusión de imágenes, fuera y dentro del álbum familiar, sin dejar de lado su ausencia. El ser humano construye sus propias vivencias a través de recuerdos que forman un muro que crece o se derrumba con el tiempo. Cada pieza, así como el conjunto de varias, se asemejan a piedras, a bloques de olvido dejados en lugares azarosos del recuerdo individual o colectivo. Más allá del álbum fotográfico tradicional se habla de desmaterialización y memoria en la fotografía digital actual, un medio invisible de rápida actuación y fácil desvanecimiento. No se contempla únicamente la fragilidad de esta memoria doméstica o familiar, si no también la fragilidad de la memoria digital, carente de materialidad.

Como opinión personal observo que estos procesos de transferencia, que aunque llevan años desarrollándose, siguen aportando, tanto en su apartado procesual como en los resultados plásticos, líneas de investigación innovadoras y sugerentes desde la hibridación de disciplinas, técnicas y procesos. Más allá de la mera incorporación de herramientas, se trata de la creación de nuevos conceptos, lenguajes y miradas. Se asientan unos conceptos de producción versus reproducción, mirada y proceso, capaces de ser interpretados en cualquier otra disciplina artística. La reproductibilidad que permite la técnica del transfer, va más allá de lo bidimensional, más allá de las bases del grabado o las placas fotopolímeras, es un recurso inédito que también se sirve de una matriz o estampa para crear una nueva huella. La diferencia entre estas técnicas reside en el significado que se le aporta al soporte donde surge la huella. Se habla de una extensión del significado o una nueva mirada. Hemos aprendido que la imagen digital puede abandonar la pantalla para fijarse espacialmente, se determina en un formato como materia, quedando asociada para siempre a su soporte. 
Los registros hablan de situaciones tanto reconocibles como propias. Lo que cambia es la forma de ver este contenido, el soporte adquiere tanto valor como el concepto. "La belleza no está tanto en la cualidad del objeto que se percibe, cuanto en efecto de los ojos en que lo perciben" ${ }^{5}$. La obra parte de la deconstrucción de múltiples biografías y recuerdos anónimos, invisibles en la memoria y en el tiempo. La fragmentación de los mismos recuerdos que almacenamos en nuestra mente, diverge entre los individuos, entre los iguales. Las fotografías del álbum familiar son imágenes y objetos físicos que existen en un tiempo y en un espacio y, por lo tanto "existen" dentro de una experiencia sociocultural. Se lleva a pensar materialmente en cuanto a la fotografía, ya que implica procesos de intención, elaboración, distribución, consumo, uso, descarte y reciclaje, todos ellos procesos que influyen en la forma en que son entendidas las fotografías y las imágenes. Es por esto, que cabe reflexionar sobre la in-materialidad de la memoria en la fotografía familiar, el peligro para esta memoria familiar que acarrea con esta falta de materialidad, se trata de la fragilidad de la memoria digital. Un punto clave de la obra reside en la divergencia de ambos tipos de fotografía, la de antes y la de ahora, la analógica y la digital, lo tradicional y lo tecnológico. Este punto es clave para comprender la in-materialidad, la recreación y representación de las fotografías domésticas de la obra. En esta desmaterialización de la fotografía digital, que a diferencia de la analógica, en cada clic se materializa en una imagen impresa, la digital se apila en discos duros y se ve únicamente en la pantalla. Por esto, se hace hincapié en la búsqueda de otras formas de ver, otras miradas.

Retomando la relación entre imagen y memoria, resulta cada vez más claro que la fotografía como memoria ya no requiere el álbum familiar para resguardarse, y las cajas de zapatos se van vaciando mientras son las redes sociales las que se llenan de imágenes. El álbum familiar quizá este en peligro de extinción, pero la fotografía, materializada o en red, es cada vez más cotidiana, más visible, más elaborada, y más constante en nuestras vidas. A expensas de ver cómo evolucionan estas imágenes, habrá que ver dónde se almacenan, dónde se mantienen a salvo del olvido, o dónde y cómo decidiremos abandonarlas.

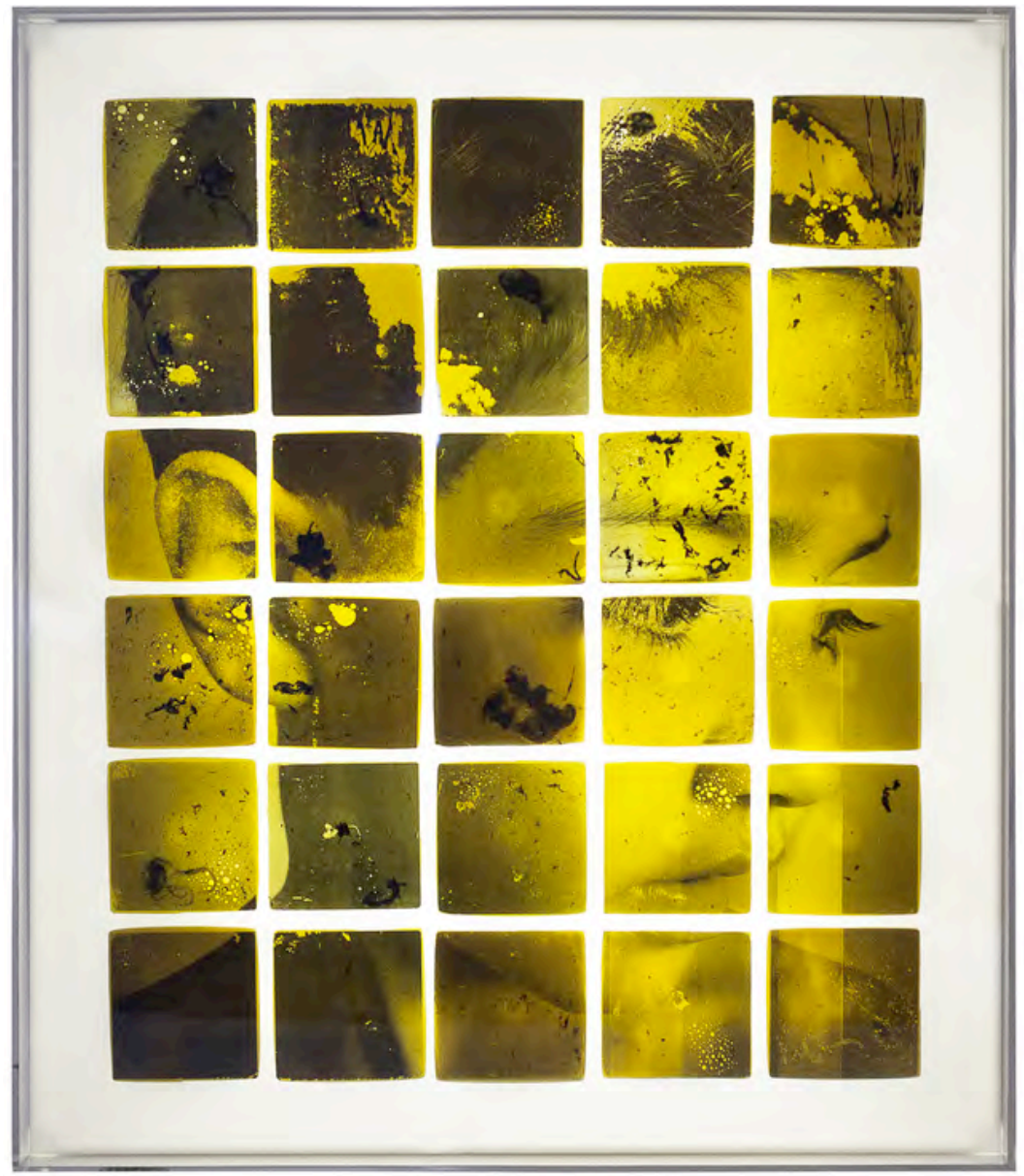

Ilustración 6 - ÁVILA, M. Al margen de lo familiar. 60 x 70cm. 2014.

\footnotetext{
${ }^{5}$ SPINOZA, B. La belleza no es racional. Carta LIV a Hugo Boxel.
} 


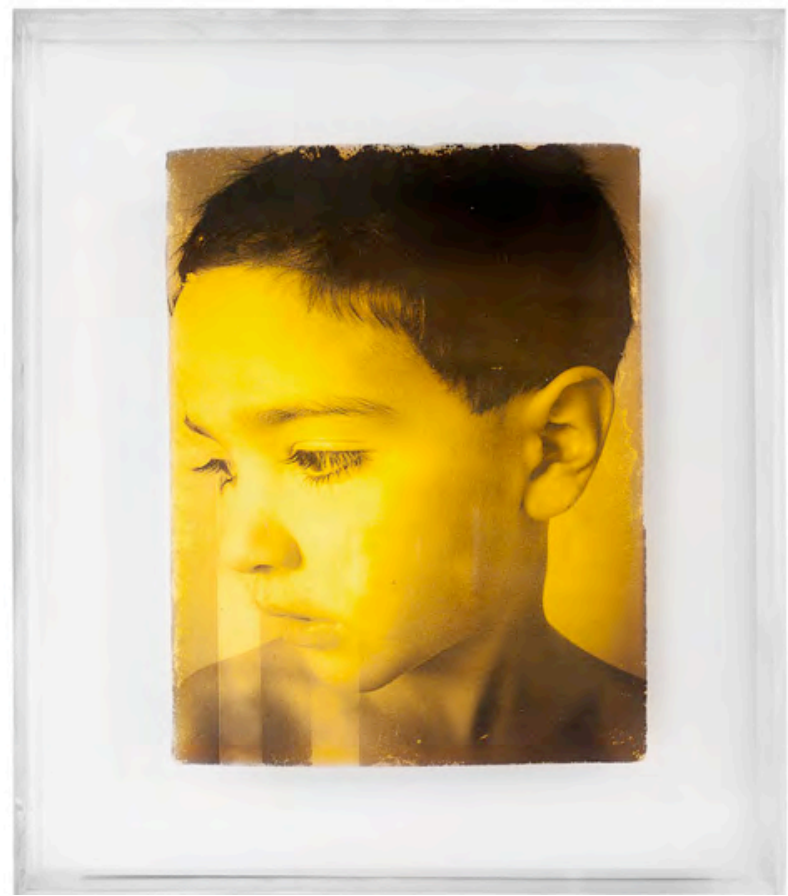

Ilustración 7 - ÁVILA, M. Al margen de lo familiar I. 28 x 33cm. 2013.

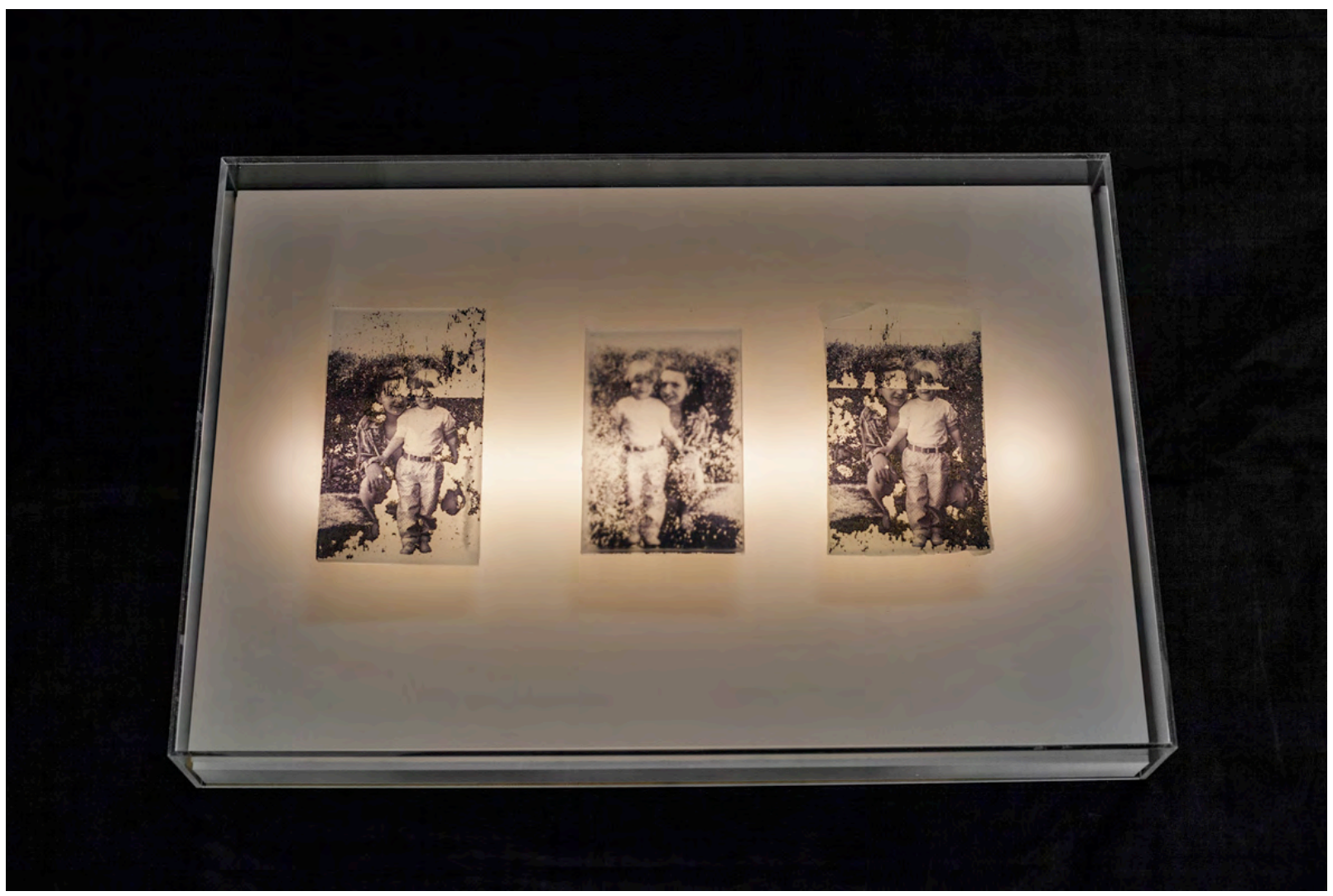

llustración 8 - ÁVILA, M. Serie Efímero. 12 x 17 cm (medidas variables). 2014. 

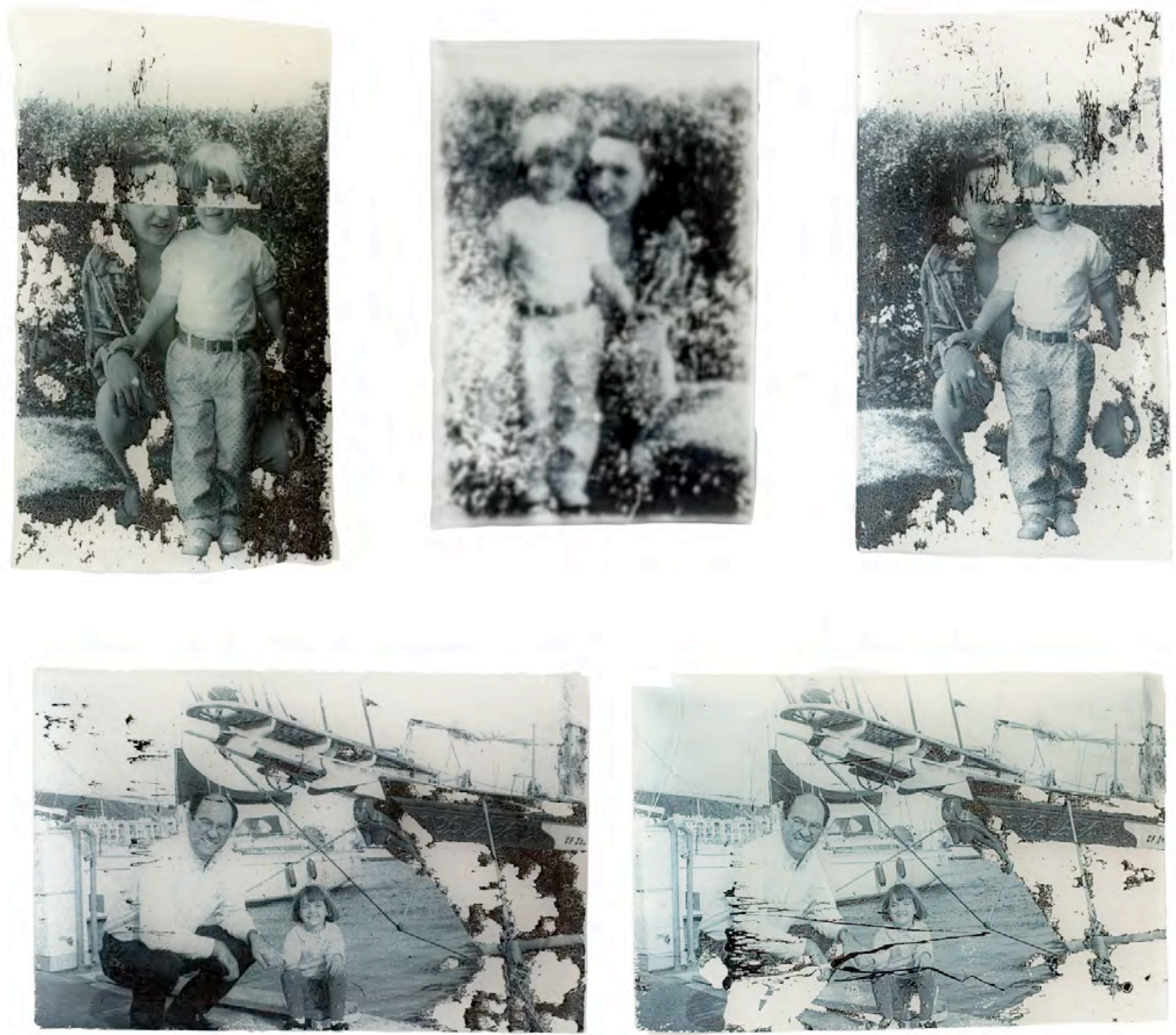

Ilustración 9 - ÁVILA, M. Serie Efímero. 12 x 17 cm. 2014. 


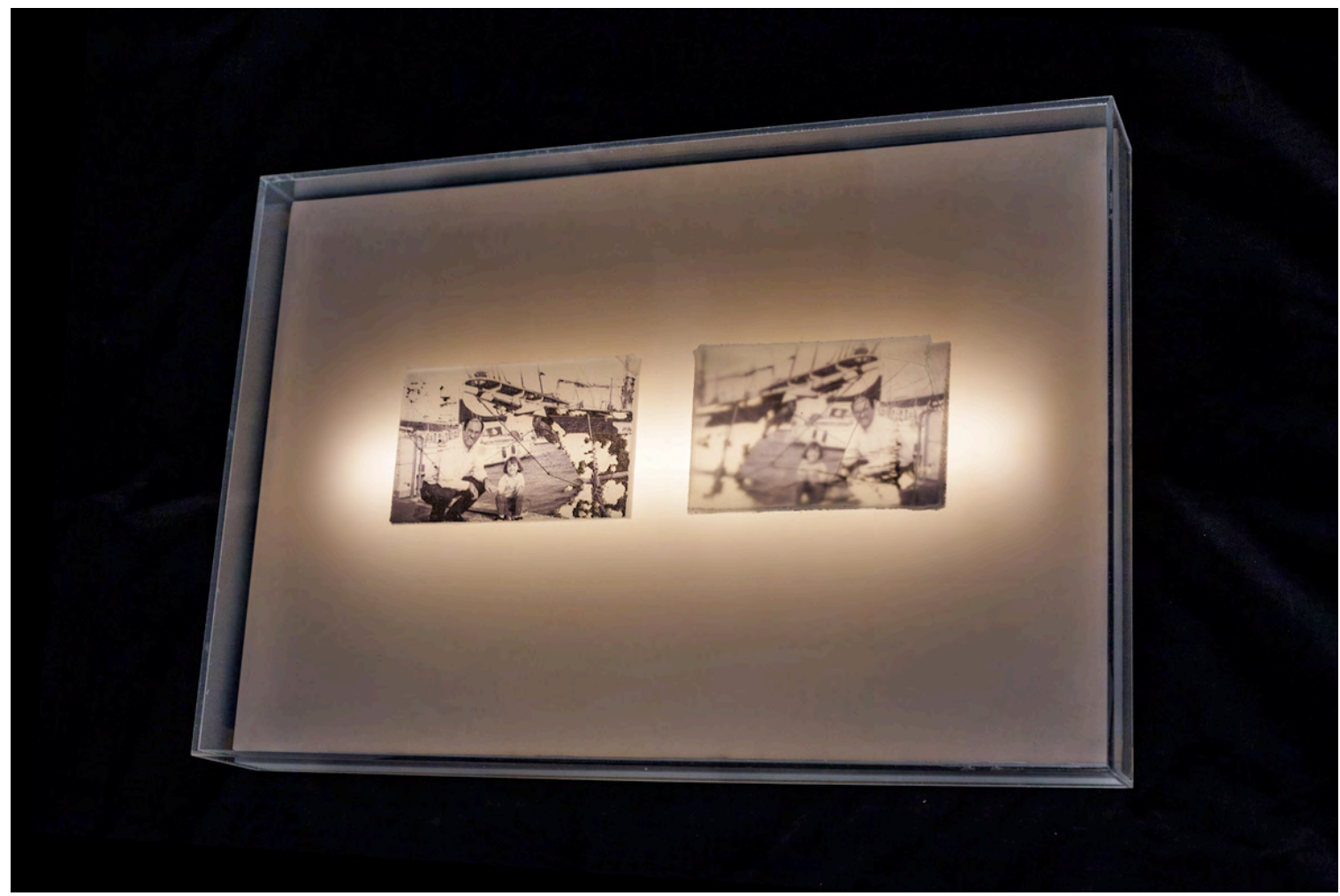

FUENTES REFERENCIALES.

ALCALÁ, J. R. La Gráfica Digital. Madrid: Fundación Marcelo Botín, 1998.

ALCALÁ, J. R. (eds.), Los Seminarios de Electrografía. Valencia: Ed. Universidad Politécnica, 1988.

ARNHEIM, R. Arte y percepción visual. Madrid: Alianza Editorial, 1979.

BARTHES, R. La cámara lúcida. Nota sobre la fotografía. Barcelona: Paidós Comunicación, 1992.

BENJAMIN, W. Autobiographische Schriften / Escritos autobiográficos. Madrid: Alianza Editorial, 1996.

Exit Express. España, Madrid: ISSN 2254-2051.

FOCAULT, M. The Archaeology of Knowledge. New York: Pantheon, 1972.

GUASCH, A. Los lugares de la memoria: El arte de archivar y recordar. En: Materia. Barcelona: Revista del departamento de Historia del Arte de la Universidad de Barcelona, 2005, ISSN: 2182-9756.

PASTOR BRAVO, J. Electrografía y Grabado. Bilbao: Caja de Ahorros Vizcaína, 1989.

TORTOSA, R. Laboratorio de una mirada: Procesos de creación a través de tecnologías electrográficas. [tesis doctoral]. Valencia: Universitat Politècnica de València, 2004.

WEIBEL, P. Arte en la era electrónica. Barcelona: Ediciones Claudia Giannetti, 1997. 